\title{
Systematic review of health economic studies in cranial neurosurgery
}

\author{
Won Hyung A. Ryu, MD, MSc, Michael M. H. Yang, MD, MBiotech, Sandeep Muram, MD, \\ W. Bradley Jacobs, MD, Steven Casha, MD, PhD, and Jay Riva-Cambrin, MD, MSc \\ Department of Clinical Neurosciences, University of Calgary, Alberta, Canada
}

\begin{abstract}
OBJECTIVE As the cost of health care continues to increase, there is a growing emphasis on evaluating the relative economic value of treatment options to guide resource allocation. The objective of this systematic review was to evaluate the current evidence regarding the cost-effectiveness of cranial neurosurgery procedures.

METHODS The authors performed a systematic review of the literature using PubMed, EMBASE, and the Cochrane Library, focusing on themes of economic evaluation and cranial neurosurgery following the Preferred Reporting ltems for Systematic Reviews and Meta-Analysis (PRISMA) guidelines. Included studies were publications of cost-effectiveness analysis or cost-utility analysis between 1995 and 2017 in which health utility outcomes in life years (LYs), quality-adjusted life years (QALYs), or disability-adjusted life years (DALYs) were used. Three independent reviewers conducted the study appraisal, data abstraction, and quality assessment, with differences resolved by consensus discussion.
\end{abstract}

RESULTS In total, 3485 citations were reviewed, with 53 studies meeting the inclusion criteria. Of those, 34 studies were published in the last 5 years. The most common subspecialty focus was cerebrovascular (32\%), followed by neurooncology (26\%) and functional neurosurgery (24\%). Twenty-eight (53\%) studies, using a willingness to pay threshold of US $\$ 50,000$ per QALY or LY, found a specific surgical treatment to be cost-effective. In addition, there were $11(21 \%)$ studies that found a specific surgical option to be economically dominant (both cost saving and having superior outcome), including endovascular thrombectomy for acute ischemic stroke, epilepsy surgery for drug-refractory epilepsy, and endoscopic pituitary tumor resection.

CONCLUSIONS There is an increasing number of cost-effectiveness studies in cranial neurosurgery, especially within the last 5 years. Although there are numerous procedures, such as endovascular thrombectomy for acute ischemic stroke, that have been conclusively proven to be cost-effective, there remain promising interventions in current practice that have yet to meet cost-effectiveness thresholds.

https://thejns.org/doi/abs/10.3171/2018.2.FOCUS17792

KEYWORDS neurosurgery; systematic review; economic evaluation; cost-effectiveness

$\mathrm{H}$ EALTH care spending in the US accounted for nearly $18 \%$ of gross domestic product in 2015 , with $4 \%$ annual growth over 2008-2013, and this growth is further projected to increase to $5.8 \%$ annually (https:// www.cdc.gov/nchs/fastats/health-expenditures.htm). ${ }^{31} \mathrm{Be}-$ cause the cost of health care continues to increase, there is a growing emphasis on assessing the relative economic value of medical treatment options to guide resource allocation. Furthermore, given that an estimated $60 \%$ of health care spending is linked to or impacted by physicians, it is essential that physicians are armed with high-quality scientific evidence on both the treatments' effectiveness and their associated financial cost. ${ }^{4}$

The trend toward value-based medicine is particularly pertinent to the field of neurosurgery, because it remains one of the most expensive areas in medicine while also being the most profitable specialty for hospitals..$^{52,67}$ Whereas economic evaluation of spine surgery has received sig-

ABBREVIATIONS CCEMG = Campbell and Cochrane Economics Methods Group; CEA = carotid endarterectomy; DALY = disability-adjusted life year; EPPI-Centre = Evidence for Policy and Practice Information and Coordinating Centre; ICER = incremental cost-effectiveness ratio; LY = life year; NHS EED = National Health Service Economic Evaluation Database; QALY = quality-adjusted life year; UK = United Kingdom; WTP = willingness to pay.

SUBMITTED December 29, 2017. ACCEPTED February 5, 2018.

INCLUDE WHEN CITING DOI: 10.3171/2018.2.FOCUS17792. 
nificant attention in the literature over the last 10 years, other subspecialties of neurosurgery have been less scrutinized. ${ }^{32,46,67}$ To our knowledge, this is the first systematic review of cost-effectiveness studies of cranial neurosurgery procedures.

\section{Methods}

\section{Search Strategy and Study Selection}

This study was registered at the International Prospective Register of Systematic Reviews (PROSPERO; CRD42017064708). We performed a systematic review of literature following the Preferred Reporting Items for Systematic Reviews and Meta-Analysis (PRISMA) guidelines, using 3 databases-PubMed, EMBASE, and the Cochrane Library - to identify all economic evaluation studies of cranial neurosurgery ${ }^{48}$ We used the National Health Service Economic Evaluation Database (NHS EED) search filter and MeSH terms to identify studies under the theme of economic evaluation and cranial neurosurgery (Table 1). ${ }^{17}$ An additional manual search was performed using references from review articles and in Google Scholar, using the same search terms as noted above.

Titles and abstracts were reviewed to identify studies published between January 1, 1995, and May 1, 2017, with a focus on comparative economic evaluation of any cranial neurosurgery procedures. Studies were excluded if they involved nonneurosurgical procedures (i.e., general surgery procedures, orthopedic procedures) or noncranial neurosurgical procedures, including spine surgery. Non-English publication, editorials, technical reports, conference abstracts, errata, book chapters, case reports, or burden-of-illness studies, and study types other than cost-effectiveness analysis or cost-utility analysis were excluded. A secondary review of full texts was done to specifically identify studies that measured health outcomes in life years (LYs), quality-adjusted life years (QALYs), or disability-adjusted life years (DALYs).

\section{Data Extraction, Synthesis, and Analysis}

For all included studies, 3 independent reviewers (W.H.A.R., M.M.H.Y., S.M.) extracted the study data using a standardized abstraction form developed a priori. Data fields included the following: author; country; currency year (specific fiscal year used in determining cost value in the study); year of publication; journal of publication; study design (cost-effectiveness analysis, cost-utility analysis); economic evaluation model (Markov model, decision tree model); perspective (health care system, health care payer, society); data source (literature, singlestudy estimates, hospital database, national database such as Medicare/Medicaid); comparators (treatments being compared); patient population (specific neurological condition of interest); time horizon (duration of time that the cost and health outcome of interest were being evaluated); discount rate (analysis to adjust for changes in cost and health outcome associated with passage of time); health outcome measure (LYs, QALYs, DALYs); sensitivity analysis (1-way, multiway, probabilistic analysis); uncertainty parameters (variables incorporated into the sensitivity analysis); study results (estimated cost and health outcome
TABLE 1. Summary of systematic literature search strategy

\begin{tabular}{|c|c|}
\hline Theme & Search Terms \\
\hline \multirow{24}{*}{$\begin{array}{l}\text { Economic } \\
\text { analysis }\end{array}$} & 1. Economics/ \\
\hline & 2. exp "costs and cost analysis"/ \\
\hline & 3. Economics, dental/ \\
\hline & 4. exp economics, hospital/ \\
\hline & 5. Economics, Medical/ \\
\hline & 6. Economics, Nursing/ \\
\hline & 7. Economics, Pharmaceutical/ \\
\hline & $\begin{array}{l}\text { 8. (economic } \$ \text { or cost or costs or costly or costing or } \\
\text { price or pricing or pharmaco-economic } \$ \text { ). ti, ab. }\end{array}$ \\
\hline & 9. (expenditure $\$$ not energy). ti, ab. \\
\hline & 10. value for money. ti, ab. \\
\hline & 11. budget\$. ti, ab. \\
\hline & 12. or/ 1-11 \\
\hline & 13. ((energy or oxygen) adj cost). ti, ab. \\
\hline & 14. (metabolic adj cost). ti, ab. \\
\hline & 15. ((energy or oxygen) adj expenditure). ti, ab. \\
\hline & 16. or/ $13-15$ \\
\hline & 17. 12 not 16 \\
\hline & 18. Letter.pt \\
\hline & 19. Editorial.pt \\
\hline & 20. Historical article.pt \\
\hline & 21. or/ $18-20$ \\
\hline & 22. 17 not 21 \\
\hline & 23. exp Animals/not humans/ \\
\hline & 24. 22 not 23 \\
\hline \multirow[t]{4}{*}{ Neurosurgery } & 1. neurosurgery \\
\hline & 2. neurologic surgery \\
\hline & 3. neurological surgery \\
\hline & 4. neurological procedure \\
\hline
\end{tabular}

$\mathrm{Ab}=$ abstract; $\mathrm{adj}=$ adjacent operator; $\exp =$ explode subject heading; $\mathrm{pt}=$ publication type; $\mathrm{ti}=$ title.

The list of the NHS EED filters used to identify all economic evaluations in PubMed and EMBASE in the literature search.

of interest, incremental cost-effectiveness ratio [ICER]); and funding source (public, industry support). Each study was categorized by neurosurgical subspecialty based on diagnosis and intervention.

For clarity in study terminology, we defined a costeffectiveness analysis as a study in which the health outcome in single natural units such as LYs was used, with results reported as monetary unit per LY saved. ${ }^{24} \mathrm{We}$ defined a cost-utility analysis as a study in which multidimensional health outcomes such as QALYs or DALYs were used, with results reported as monetary unit per QALY or DALY gained. ${ }^{24}$ Cost-effectiveness ratio refers to cost per health outcome (i.e., LY or QALY) for a specific intervention in question. The term ICER refers to the ratio of difference in the cost of the 2 interventions over the difference in health outcomes.

Based on the previously published report by Zygourakis and Kahn, which highlighted significant heterogeneity 
of economic evaluation studies in neurosurgery, including study methodology (i.e., simple cost comparison versus full economic evaluation using cost-utility analysis) and primary outcomes measures (QALYs, LYs, DALYs), data analysis was performed in a descriptive manner. ${ }^{67}$ For each study, the reported cost-effectiveness ratio or ICER was converted from their initial value to 2016 US dollars by using the Campbell and Cochrane Economics Methods Group (CCEMG) and the Evidence for Policy and Practice Information and Coordinating Centre (EPPI-Centre) (i.e., CCEMG-EPPI-Centre) cost converter. ${ }^{55}$ This online tool was developed based on published research from the CCEMG-EPPI-Centre. ${ }^{55}$ It allows standardized comparison of cost variables in multiple studies by adjusting for differences in currencies and currency year. For studies that failed to report the currency year, the year of publication was used as the surrogate currency year.

The converted cost-effectiveness ratio or ICER was then assessed against a commonly used willingness to pay (WTP) threshold of US\$50,000 per health outcome (i.e., QALYs or LYs). ${ }^{20}$ The WTP threshold represents a theoretical maximum cost of an intervention that is deemed acceptable by the health care payer in order to achieve a specified health outcome such as QALYs or LYs. ${ }^{20}$ The specific intervention being studied was deemed dominant over the alternative treatment option if it met the following criteria: 1) less costly and 2) led to improved health out- come. For studies included in our systematic review that reported sensitivity analysis, we extracted variables that were found to be influential in the reported cost-effectiveness ratio (i.e., cost of procedure, discount rate).

Three independent reviewers performed quality assessment of the studies by using the Drummond checklist for assessing economic evaluations. ${ }^{9}$ This validated questionnaire consists of 10 items that address key requirements of economic studies in health care, with scores of 8 deemed as high quality. Discrepancies in scores were resolved through discussion between the reviewers.

\section{Results}

\section{Search Results and Study Characteristics}

In total, 3485 citations were reviewed, of which 53 studies met the inclusion criteria (Fig. 1); 64\% (34 studies) of these were published in the last 5 years (Fig. 2). ${ }^{1-3}$, 5-8,10-16,19,21,22,25-30,33-43,45,47,49-51,53,54,56-66,68 The most common subspecialty focuses of these cost-effectiveness studies were cerebrovascular neurosurgery (32\%), followed by neurooncology (26\%) and functional neurosurgery (24\%) (Fig. 3). The preponderance of studies originated in the US (47\%), followed by the United Kingdom (UK; 9\%) and the Netherlands (9\%) (Fig. 4). Twenty-seven studies (51\%) did not specify the source of funding. Of the studies that included funding source, $30 \%$ were supported by a public

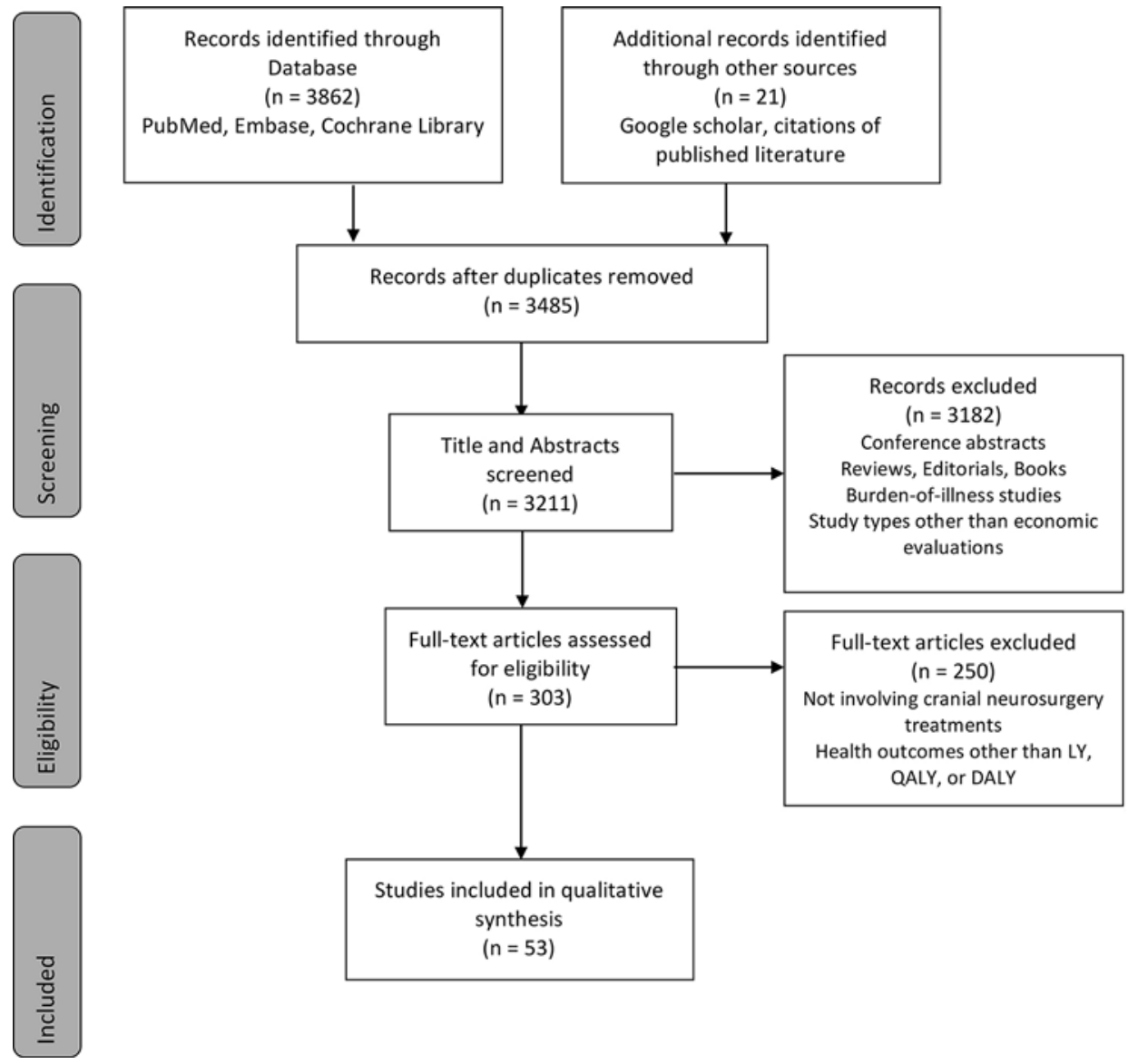

FIG. 1. Flowchart of the systematic search strategy and study selection based on the PRISMA guidelines. 


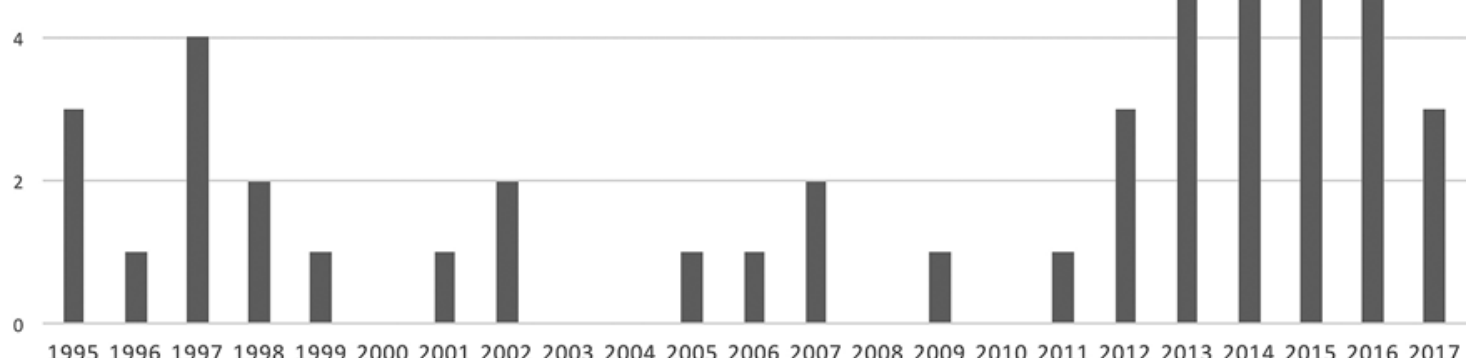
19951996199719981999200020012002200320042005200620072008200920102011201220132014201520162017 Year of publication

FIG. 2. Bar graph showing economic evaluation studies included in the systematic review based on year of publication.

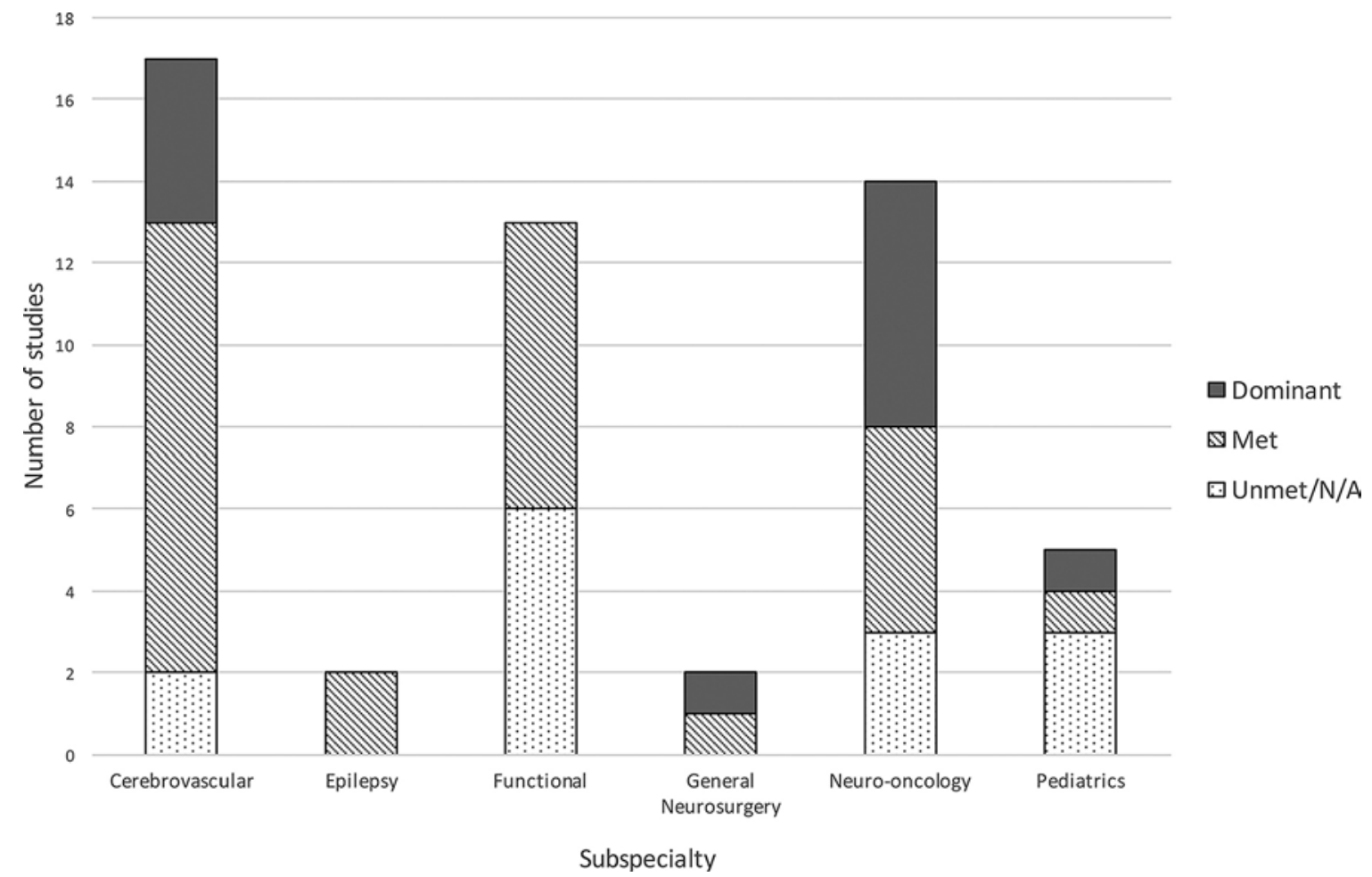

FIG. 3. Bar graph showing distribution of economic evaluation studies based on subspecialty of neurosurgery. Studies are organized based on the reported cost-effectiveness ratio against the WTP threshold of US $\$ 50,000$ per health outcome (i.e., QALY, LY). The specific intervention being studied was deemed dominant over the alternative treatment option if it met the following criteria: 1) less costly and 2) led to improved health outcome. If the cost-effectiveness ratio of the intervention in question was less than US $\$ 50,000$ per health outcome, it was categorized as met. If the cost-effectiveness ratio of the intervention in question was more than US $\$ 50,000$ per health outcome, it was categorized as unmet. N/A = not applicable. 


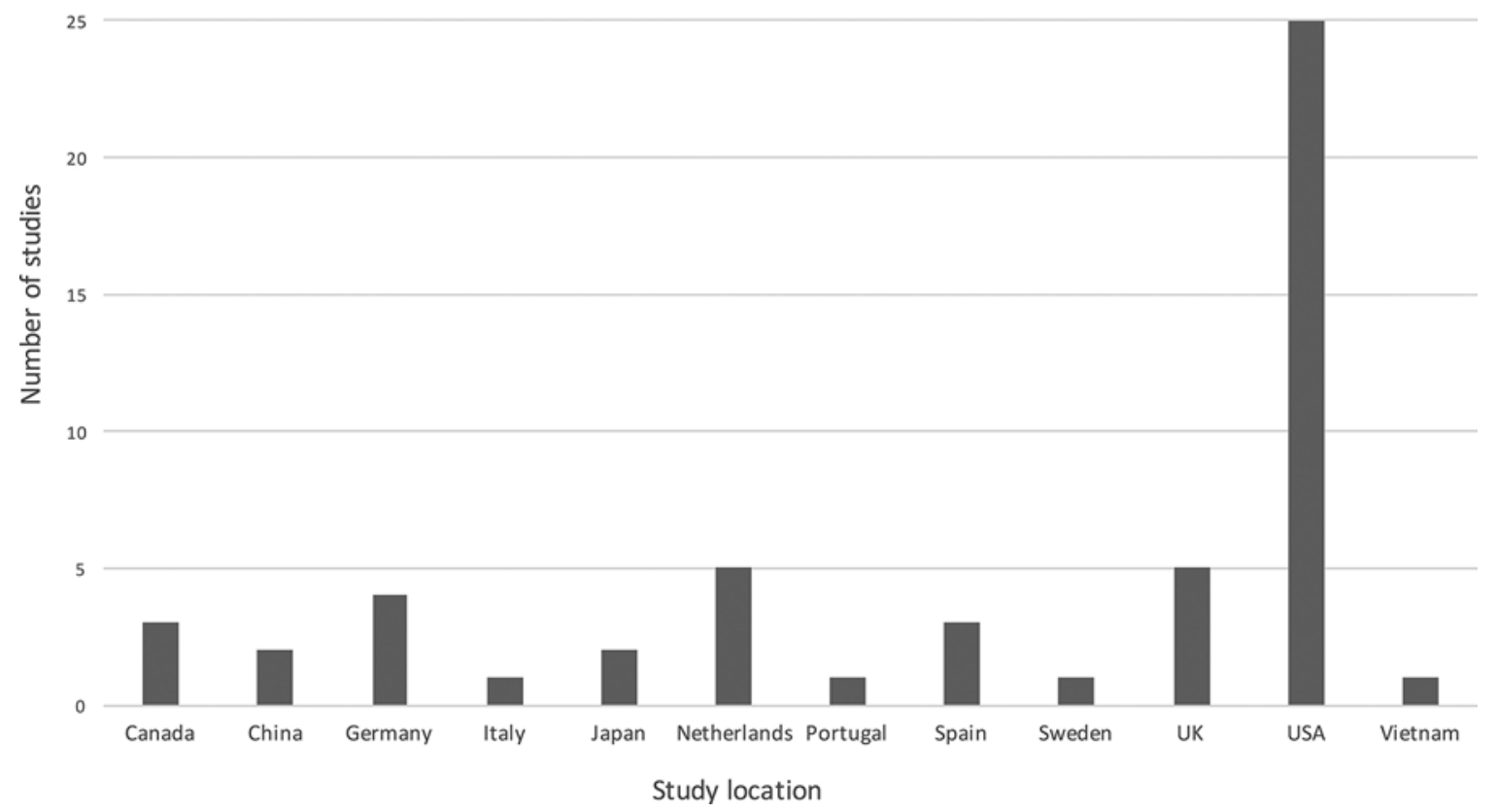

FIG. 4. Bar graph showing distribution of economic evaluation studies based on location.

source (i.e., Heart \& Stroke Foundation, National Institutes of Health), whereas 19\% received industry support (i.e., Medtronic, Johnson \& Johnson).

\section{Study Findings and Study Quality}

Detailed summaries of study results and methodology are included in Tables 2 and 3. Twenty-eight (53\%) studies found a specific surgical treatment to be cost-effective by using a WTP threshold of US\$50,000 per health outcome (i.e., QALYs or LYs) (Fig. 3). In addition, there were 11 (21\%) studies that found the specific surgical option to be dominant (both cost saving and having superior outcome). Treatments found to be dominant included endovascular thrombectomy for acute ischemic stroke compared to standard medical care; transsphenoidal surgery compared to medical treatment for prolactinoma; intraoperative mapping for low-grade glioma versus standard resection; carotid endarterectomy (CEA) compared to medical therapy for carotid stenosis; endoscopic pituitary tumor resection compared to microscopic tumor resection; and stereotactic radiosurgery compared to open surgery for metastatic brain tumors. Eight studies $(15 \%$; 3 neurooncology, 2 cerebrovascular, 2 functional, 1 epilepsy) incorporated indirect cost (i.e., loss of potential income due to illness or treatment morbidity, caregiver's time) as part of their economic evaluation.

The majority of the studies (87\%) performed a sensitivity analysis to address uncertainties in the data used for their economic analysis, with the most common method being 1-way deterministic sensitivity analysis, followed by probabilistic sensitivity analysis (Table 4). Thirty-eight of 53 studies (72\%) reported using 1-way deterministic sensitivity analysis, which considers a wide range of values for a specific variable within the model (e.g., cost of treatment, patient age, complication rate, discount rate) to assess the effect of individual variables on the overall cost-effectiveness ratio. Twenty-four of 53 studies $(45 \%)$ reported using probabilistic sensitivity analysis, which determines the probability of the intervention being cost-effective at certain WTP thresholds by randomly varying every input datum. The most common variables tested in sensitivity models were cost (58\%), effectiveness of the treatment in question (43\%), age (30\%), and discount rate (26\%).

Of the studies included in our review, $43(81 \%)$ were judged to be high quality (score $>8$ ) on the basis of the Drummond checklist (range 5-10). The most frequent reason for lower score was failure to address the following requirements: 1) adjusting cost and health outcome for differential timing $(23 \%)$; 2 ) providing comprehensive descriptions of the competing treatment options (20\%); and 3 ) performing sensitivity analysis for uncertainty parameters in the economic model (14\%).

\section{Discussion}

To our knowledge, this is the first systematic review to examine and summarize the current body of evidence on the cost-effectiveness of cranial neurosurgery. We identified 53 studies that evaluated a specific operative neurosurgical intervention against an alternative treatment in a cost-effectiveness context. These articles addressed topics in all subspecialties of neurosurgery, including pediatrics, functional, epilepsy, cerebrovascular, general neurosurgery, and neurooncology; however, cerebrovascular, neurooncology, and functional neurosurgery were the most prevalent. 


\begin{tabular}{|c|c|c|c|c|}
\hline Authors \& Year & $\begin{array}{l}\text { Currency } \\
\text { Year }\end{array}$ & Patient Population & $\begin{array}{c}\text { Comparators } \\
\text { (intervention of interest vs alternative option) }\end{array}$ & $\begin{array}{c}\text { WTP } \\
\text { Threshold } \\
2016 \\
\text { (US } \$ 50,000 / \\
\text { QALY or LY) }\end{array}$ \\
\hline Alali et al., 2014 & 2013 & Traumatic brain injury & Decompressive craniectomy vs barbiturate coma & Met \\
\hline Aronsson et al., 2016 & 2015 & Acute ischemic stroke & Endovascular thrombectomy vs standard medical care & Dominant \\
\hline Bowen et al., 2012 & 2010 & Pediatric epilepsy & Surgery vs medical management & Dominant \\
\hline Cho et al., 2006 & $2000-2003$ & Benign cranial base tumors & GKS vs open surgery & Met \\
\hline Dams et al., 2016 & 2013 & PD & DBS of STN + medical treatment vs standard medical care & Met \\
\hline Dams et al., 2013 & 2010 & PD & DBS vs standard medical care & Met \\
\hline de Kinderen et al., 2015 & 2013 & Pediatric epilepsy & KD vs VNS vs standard medical care & Unmet \\
\hline Eggington et al., 2014 & 2011 & PD & DBS vs standard medical care & Met \\
\hline Esteves et al., 2015 & 2012 & HGGs & 5-ALA fluorescence-guided surgery vs standard surgery & Met \\
\hline Fallah et al., 2016 & 2016 & $\begin{array}{l}\text { Pediatric epilepsy w/ tuberous } \\
\text { sclerosis }\end{array}$ & Surgical resection vs KD vs VNS vs addition of 3rd AED & Unmet \\
\hline Gaetani et al., 1998 & NR & Intracranial aneurysms & Early vs delayed surgery for ruptured aneurysm & Met \\
\hline $\begin{array}{l}\text { Ganesalingam et al., } \\
\quad 2015\end{array}$ & $2013-2014$ & Acute ischemic stroke & Endovascular thrombectomy vs standard medical care & Met \\
\hline Garside et al., 2007 & NR & HGGs & Carmustine wafers + surgery + RT vs surgery + RT & Unmet \\
\hline Garton et al., 2002 & 2000 & Pediatric hydrocephalus & ETV vs shunt placement & Met \\
\hline Greving et al., 2009 & 2005 & UIAs & Surgery vs endovascular coiling vs observation & Met \\
\hline Helmers et al., 2012 & 2010 & Pediatric epilepsy & $\begin{array}{l}\text { VNS insertion + medical therapy vs standard medical care } \\
\text { (pre-VNS insertion) }\end{array}$ & $N A^{*}$ \\
\hline Hofmeijer et al., 2013 & 2009 & Middle cerebral artery infarction & Surgical decompression vs standard medical care & Unmet \\
\hline Jethwa et al., 2016 & 2013 & Prolactinoma & Transsphenoidal surgery vs standard medical care & Dominant \\
\hline Johnston et al., 1999 & 1997 & UIAs & Surgery vs endovascular coiling vs observation & Met \\
\hline Jordan et al., 1996 & 1992 & Arteriovenous malformation & Embolization + surgery vs surgery alone & Met \\
\hline Kallmes et al., 1998 & 1996 & UIAs in nonsurgical candidates & Endovascular coiling vs observation & Met \\
\hline Kameda et al., 2017 & NR & iNPH & Shunt (VP, LP) vs no shunt & Met \\
\hline Kawamoto et al., 2016 & 2014 & PD & 1) DBS vs standard medical care; 2) early DBS vs late DBS & Met \\
\hline Khan et al., 2012 & 2010 & Carotid artery stenosis & CAS vs CEA & Unmet \\
\hline King et al., 1995 & 1992 & Asymptomatic UIAs & Surgery vs observation & Met \\
\hline King et al., 1997 & 1994 & $\begin{array}{l}\text { Intractable temporal lobe } \\
\text { epilepsy }\end{array}$ & ATL vs standard medical care & Met \\
\hline Koffijberg et al., 2011 & 2005 & Ruptured aneurysms & Endovascular coiling or surgery vs observation & Met \\
\hline Kunz et al., 2016 & 2015 & Acute ischemic stroke & Endovascular thrombectomy vs standard medical care & Met \\
\hline Langfitt, 1997 & 1995 & Medically intractable epilepsy & ATL vs standard medical care & Met \\
\hline Leppert et al., 2015 & 2012 & Acute ischemic stroke & Endovascular thrombectomy vs standard medical care & Met \\
\hline Lobotesis et al., 2016 & 2014 & Acute ischemic stroke & Endovascular thrombectomy vs standard medical care & Dominant \\
\hline Martino et al., 2013 & 2011 & WHO Grade II glioma & $\begin{array}{l}\text { Intraop electrical stimulation mapping for resection vs stand- } \\
\text { ard tumor resection }\end{array}$ & Dominant \\
\hline Mclntosh et al., 2016 & 2010 & PD & DBS vs standard medical care & Unmet \\
\hline Mehta et al., 1997 & NR & Single brain metastases & $\mathrm{SRS}+\mathrm{RT}$ vs RT alone vs resection + RT & Met \\
\hline Nussbaum et al., 1996 & NR & Stroke & CEA vs observation alone vs aspirin therapy & Dominant \\
\hline Ooms et al., 2017 & NR & Obsessive-compulsive disorder & DBS vs standard medical care & Unmet \\
\hline Pollock \& Ecker, 2005 & 2000 & Trigeminal neuralgia & MVD vs glycerol rhizotomy vs SRS & Met \\
\hline Porter et al., 1997 & 1995 & Arteriovenous malformation & Surgery vs SRS & Met \\
\hline Ravikumar et al., 2017 & 2016 & Essential tremor & FUS vs SRS vs DBS & Met \\
\hline Rudmik et al., 2015 & 2014 & Pituitary adenoma & Endoscopic vs microscopic tumor resection & Dominant \\
\hline Rutigliano et al., 1995 & NR & Single brain metastases & SRS vs resection vs RT alone & Unmet \\
\hline Shireman et al., 2017 & 2015 & Acute ischemic stroke & Stent retriever thrombectomy vs standard medical care & Dominant \\
\hline
\end{tabular}




\begin{tabular}{|c|c|c|c|c|}
\hline Authors \& Year & $\begin{array}{l}\text { Currency } \\
\text { Year }\end{array}$ & Patient Population & $\begin{array}{l}\text { Comparators } \\
\text { (intervention of interest vs alternative option) }\end{array}$ & $\begin{array}{c}\text { WTP } \\
\text { Threshold } \\
2016 \\
\text { (US } \$ 50,000 / \\
\text { QALY or LY) }\end{array}$ \\
\hline Sivakanthan et al., 2014 & 2011 & Trigeminal neuralgia & MVD vs SRS vs percutaneous rhizotomy & Met \\
\hline Slof et al., 2015 & NR & WHO Grade IV glioma & $\begin{array}{l}\text { 5-ALA-induced fluorescence-guided glioma surgery vs } \\
\text { standard surgery }\end{array}$ & Met \\
\hline Stroupe et al., 2014 & 2010 & PD & DBS of GPi vs DBS of STN & Unmet \\
\hline $\begin{array}{l}\text { Tomaszewski \& Hol- } \\
\quad \text { loway, } 2001\end{array}$ & 2000 & Late-stage PD & DBS vs standard medical care & Unmet \\
\hline Valldeoriola et al., 2007 & NR & PD & DBS of STN vs standard medical care & Unmet \\
\hline Voigt \& Barnett, 2016 & 2015 & $\begin{array}{l}\text { HGG where maximal resection } \\
\text { not feasible }\end{array}$ & $\begin{array}{l}\text { Brain LITT system vs current treatments (craniotomy w/ or } \\
\text { w/o Gliadel wafer) }\end{array}$ & Met \\
\hline Vuong et al., 2013 & 2009 & $1-2$ brain metastases & SRS vs resection & Dominant \\
\hline Vuong et al., 2012 & 2007 & Brain metastasis & SRS vs resection & Dominant \\
\hline Wernicke et al., 2016 & $2008-2010$ & Brain metastasis & Resection $+{ }^{131} \mathrm{Cs}$ intraop brachytherapy vs resection + SRS & Dominant \\
\hline Zhu et al., 2014 & 2009 & PD & DBS of STN vs standard medical care & Unmet \\
\hline Zygourakis et al., 2014 & $2010-2013$ & Vestibular schwannoma & Surgery vs RT (GKS) vs observation & Unmet \\
\hline
\end{tabular}

$\mathrm{AED}=$ antiepileptic drug; $\mathrm{ATL}=$ anterior temporal lobectomy; $\mathrm{CAS}=$ carotid artery stenting; $\mathrm{DBS}$ = deep brain stimulation; ETV = endoscopic third ventriculostomy; FUS = focused ultrasound; GKS = Gamma Knife surgery; $\mathrm{GPi}$ = globus pallidus internus; $\mathrm{HGG}=$ high-grade glioma; $\mathrm{iNPH}=$ idiopathic normal pressure hydrocephalus; $\mathrm{KD}$ $=$ ketogenic diet; LITT = laser interstitial thermal therapy; $\mathrm{LP}=$ lumboperitoneal; $\mathrm{MVD}=$ microvascular decompression; $\mathrm{NA}=$ not applicable; $\mathrm{NR}=$ not reported; $\mathrm{PD}=$ Parkinson disease; $\mathrm{RT}=$ radiation therapy; SRS = stereotactic radiosurgery; $\mathrm{STN}=$ subthalamic nucleus; UIA = unruptured intracranial aneurysm; VNS = vagal nerve stimulator; VP = ventriculoperitoneal; 5-ALA = 5-aminolevulinic acid.

The cost-effectiveness ratio of the intervention in question (i.e., cost per health outcome) was compared against the WTP threshold of US $\$ 50,000 / Q A L Y$ or LY.

* Study did not report a cost-effectiveness ratio or ICER, and therefore we were unable to determine whether intervention met the WTP threshold.

The findings of our review reflect a growing emphasis on incorporating economic value within neurosurgical decision making and continuing the growth of economic evaluation research in neurosurgery. A previous nonsystematic review by Zygourakis and Kahn examined 26 economic evaluation studies of neurosurgery published before 2014; however, they found that many were not true cost-effectiveness studies. ${ }^{67}$ In addition, a number of those studies focused on nonoperative practices such as the use of diagnostic imaging for brain injury. ${ }^{23}$ In contrast, we found 30 studies focused specifically on operative neurosurgical care that were published between 2013 and 2017. More importantly, $74 \%$ of the 53 included studies found that the treatment evaluated was dominant or cost-effective at a WTP threshold of US\$50,000 per health outcome (i.e., QALYs, LYs).

Eleven studies $(21 \%)$ found that a treatment was economically dominant compared to the alternative considered. Three of these studies highlighted the cost-effectiveness benefit of endovascular thrombectomy for acute ischemic stroke, ${ }^{2,40,56}$ and reflect the recent advances from multiple clinical trials, such as the ESCAPE (Endovascular Treatment for Small Core and Proximal Occlusion Ischemic Stroke) trial, which show a significant increase in the number of functionally independent patients after endovascular thrombectomy. ${ }^{18}$ A similar long-term economic benefit of reduced stroke-related disability was reported by Nussbaum et al., who found CEA dominant over medical management in patients with symptomatic carotid stenosis. ${ }^{45}$ The impact of improved long-term patient outcome in cost-effectiveness analysis was also demonstrated in surgical management for medically intractable epilepsy, awake craniotomy for low-grade glioma resection, and pituitary tumor resection. ${ }^{3,25,41,53}$ In these studies, higher direct costs often related to cost of surgery were compensated by long-term benefits and lower follow-up costs. ${ }^{3,25}$, ${ }^{41,53}$ In contrast, 3 studies evaluating the cost-effectiveness of metastatic brain tumor treatment, for which life expectancy remains more limited, found that options with lower procedural cost and lower postoperative morbidity were dominant. These included stereotactic radiosurgery and intraoperative brachytherapy ${ }^{63-65}$

Compared with the findings of Zygourakis and Kahn in their earlier review of the literature, certain subspecialties of neurosurgery, particularly cerebrovascular and neurooncology, have contributed a significant number of cost-effectiveness studies (31/53 studies in our review), particularly within the last 5 years ${ }^{67}$ However, other subspecialties (epilepsy, neuro-critical care, and pediatrics) remain poorly represented in the health economics literature, with only a few published studies. We view this as a call-to-arms and an opportunity to conduct health economic studies examining treatments within these particular subspecialties.

\section{Limitations of the Study}

The literature we identified was unfortunately too het- 

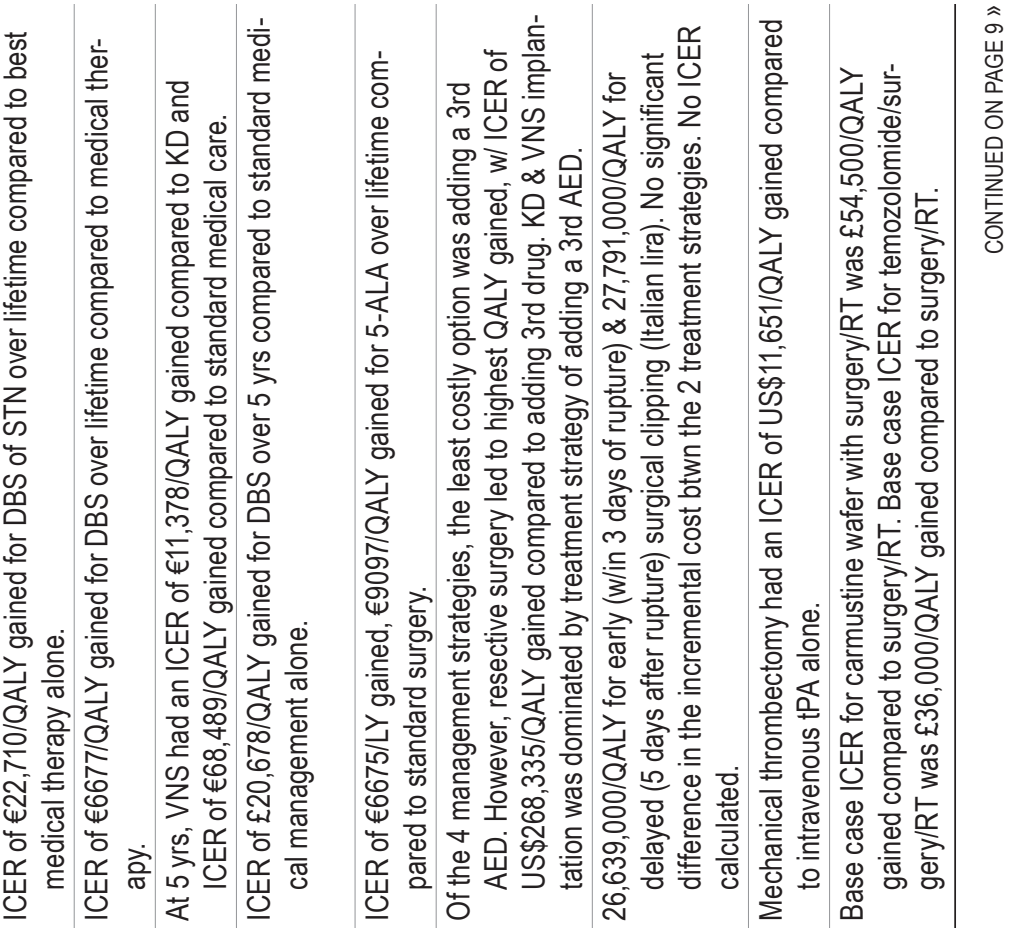

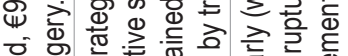

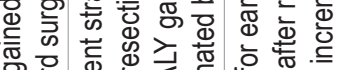

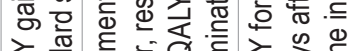

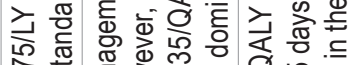

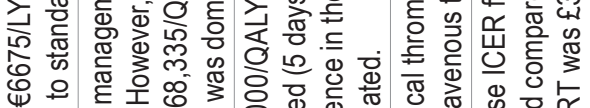

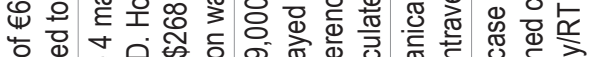

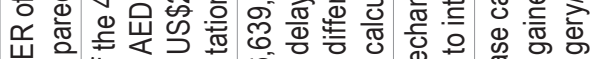

U U

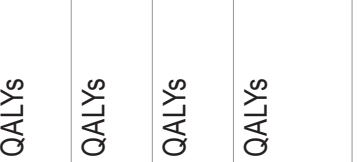

$\frac{0}{\sum^{\infty}}$

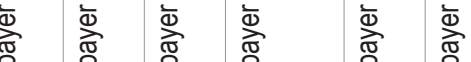

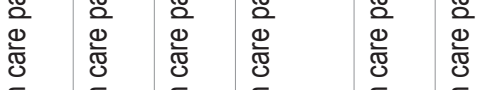

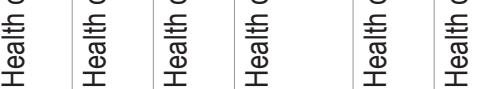

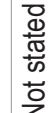

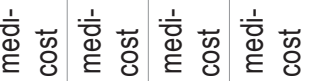

芯 五

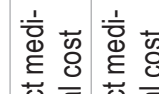

式

容

兽

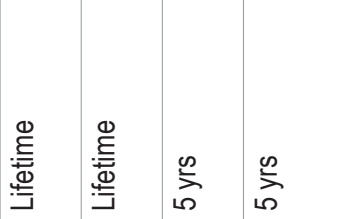

बं क्ञ⿰冫欠

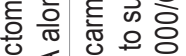

(1) 힌

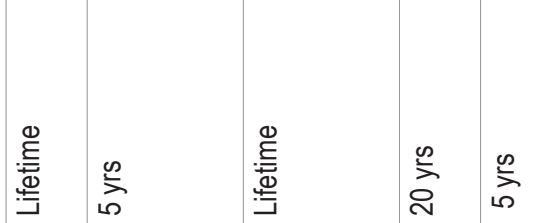

\section{(ब)}

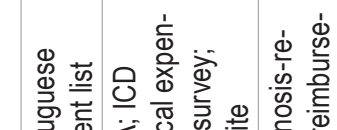

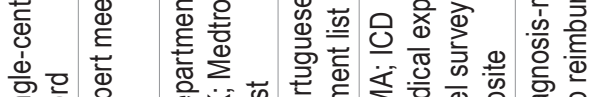

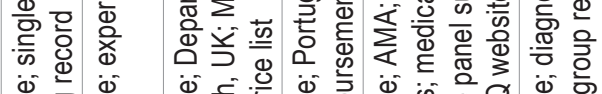

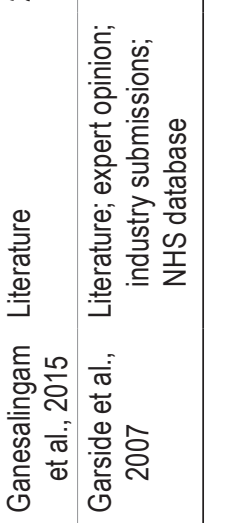




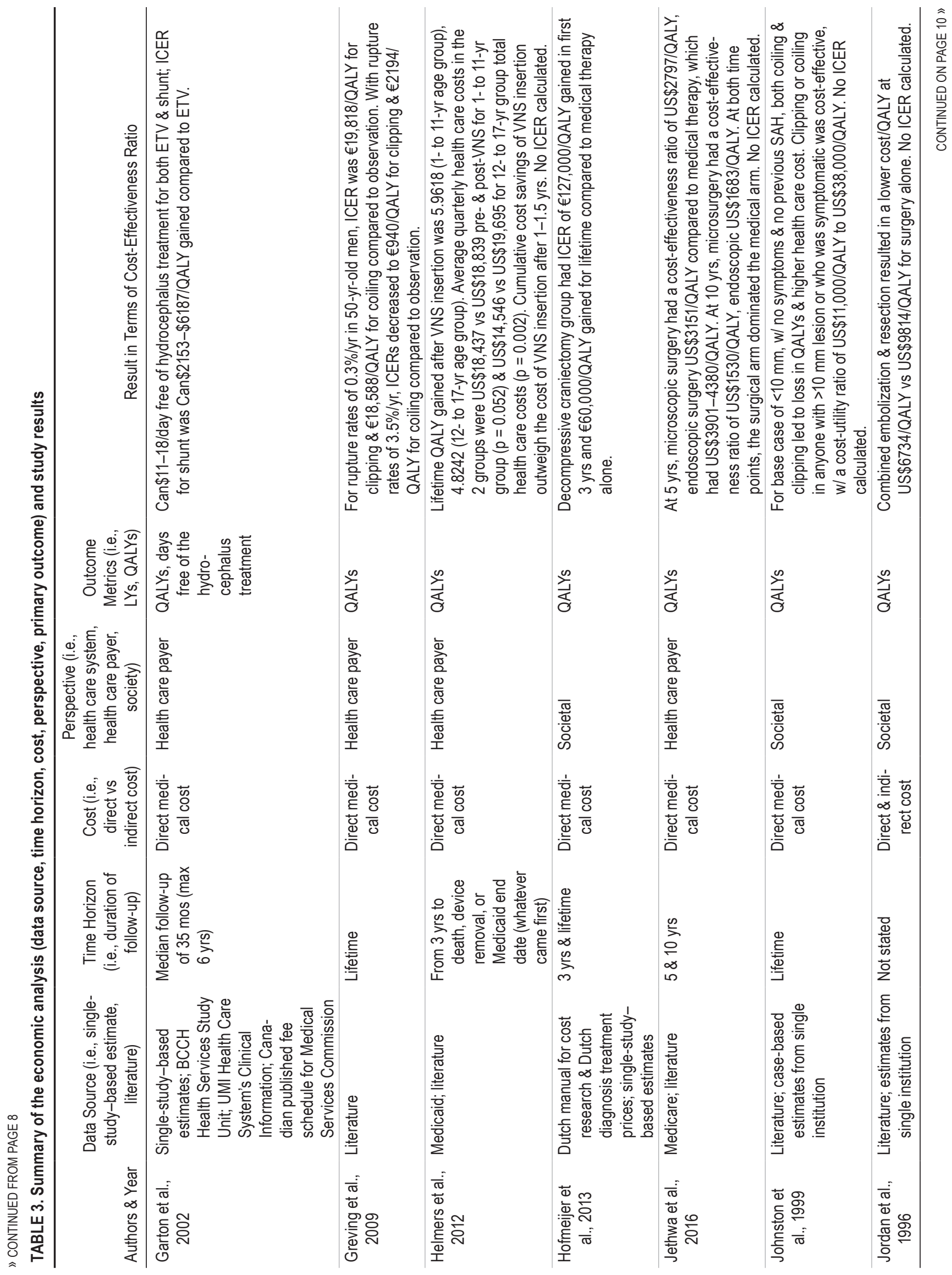




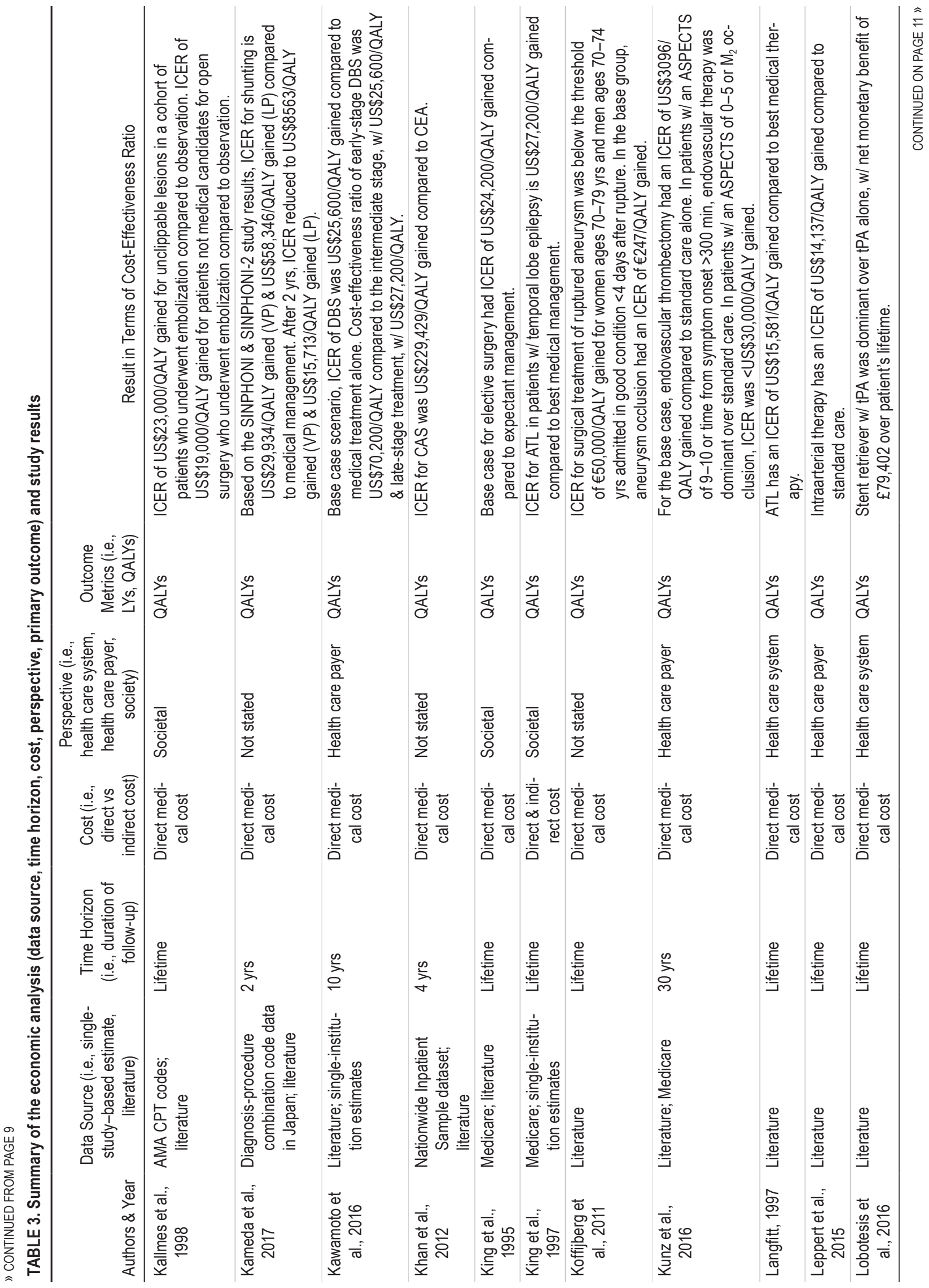




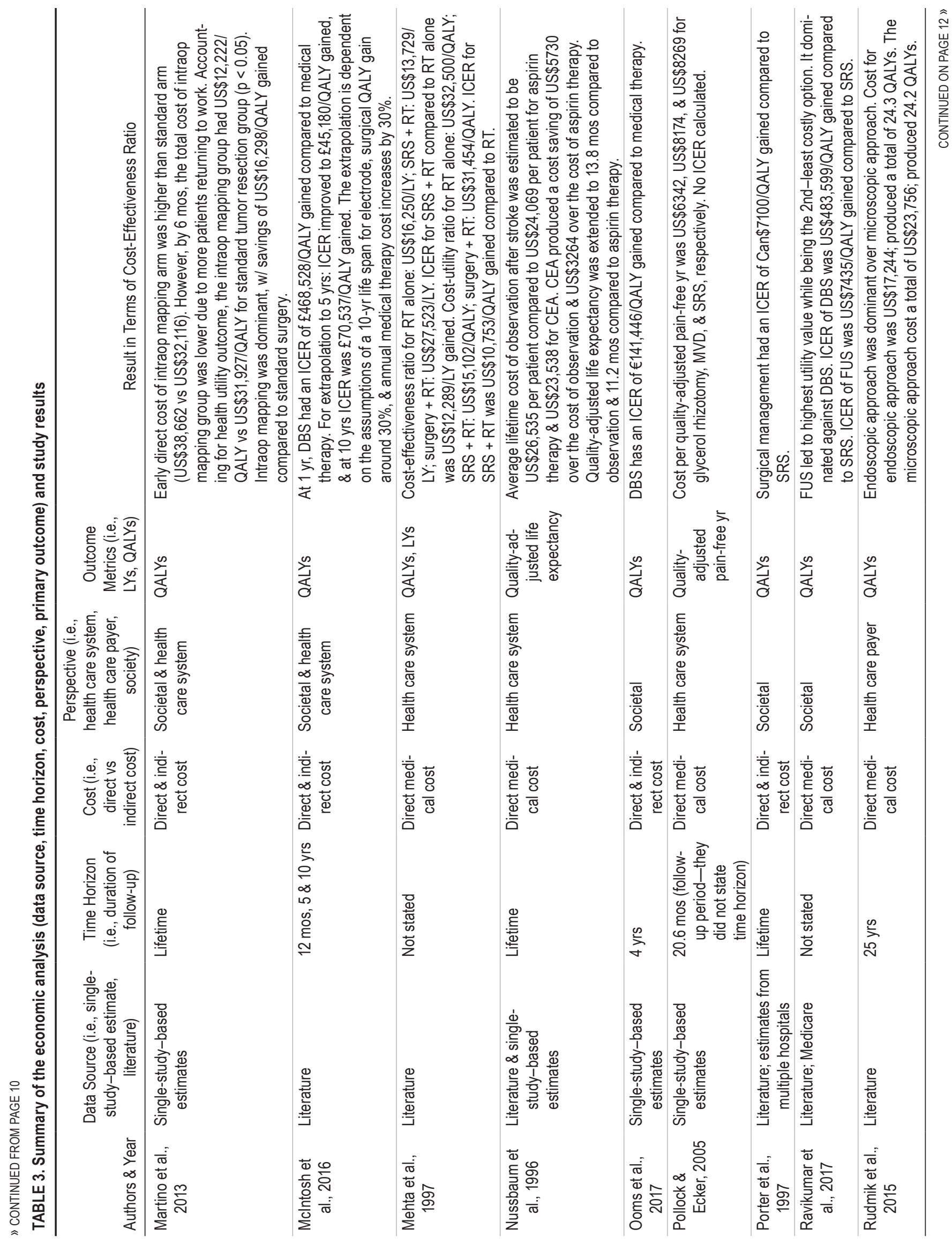




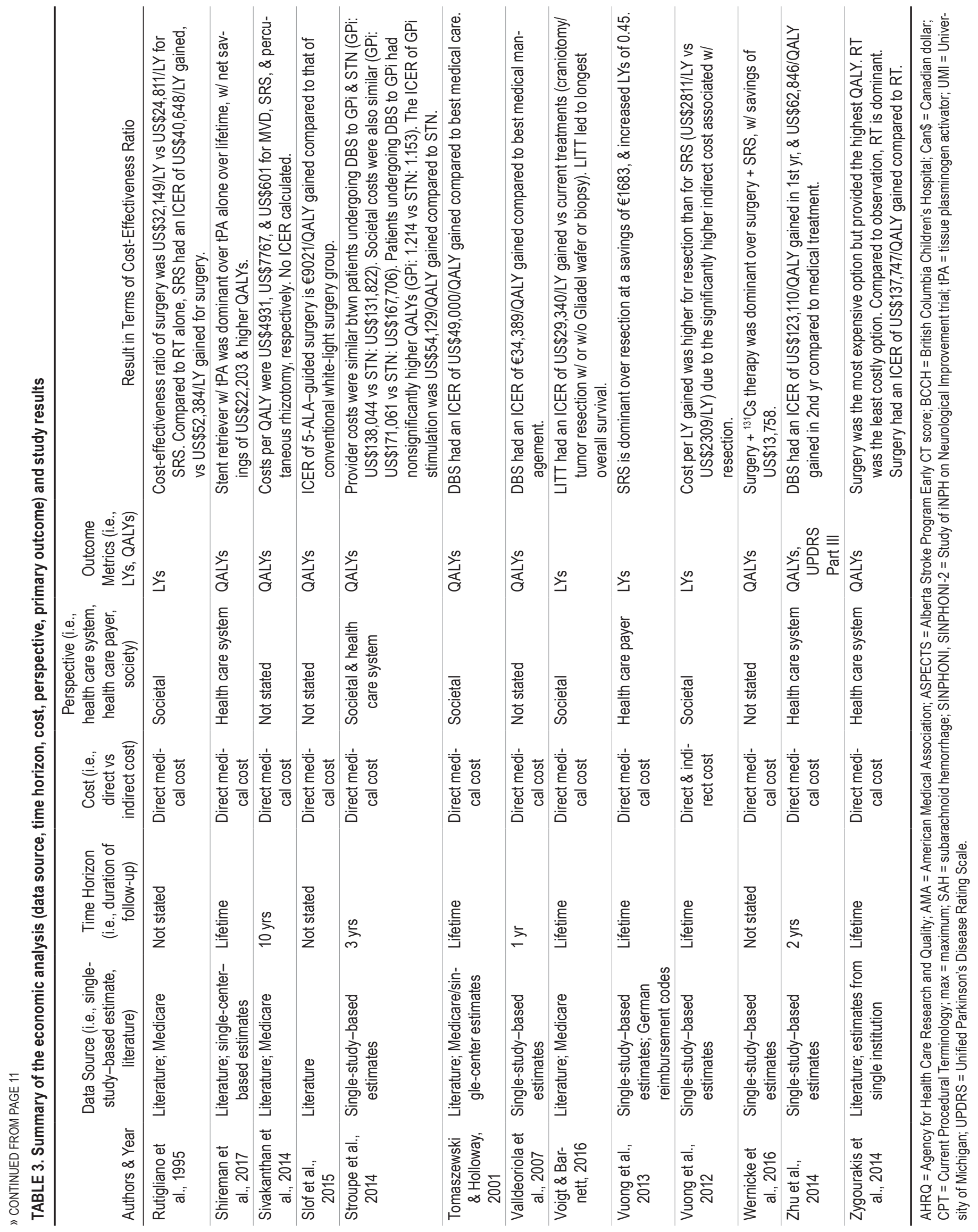




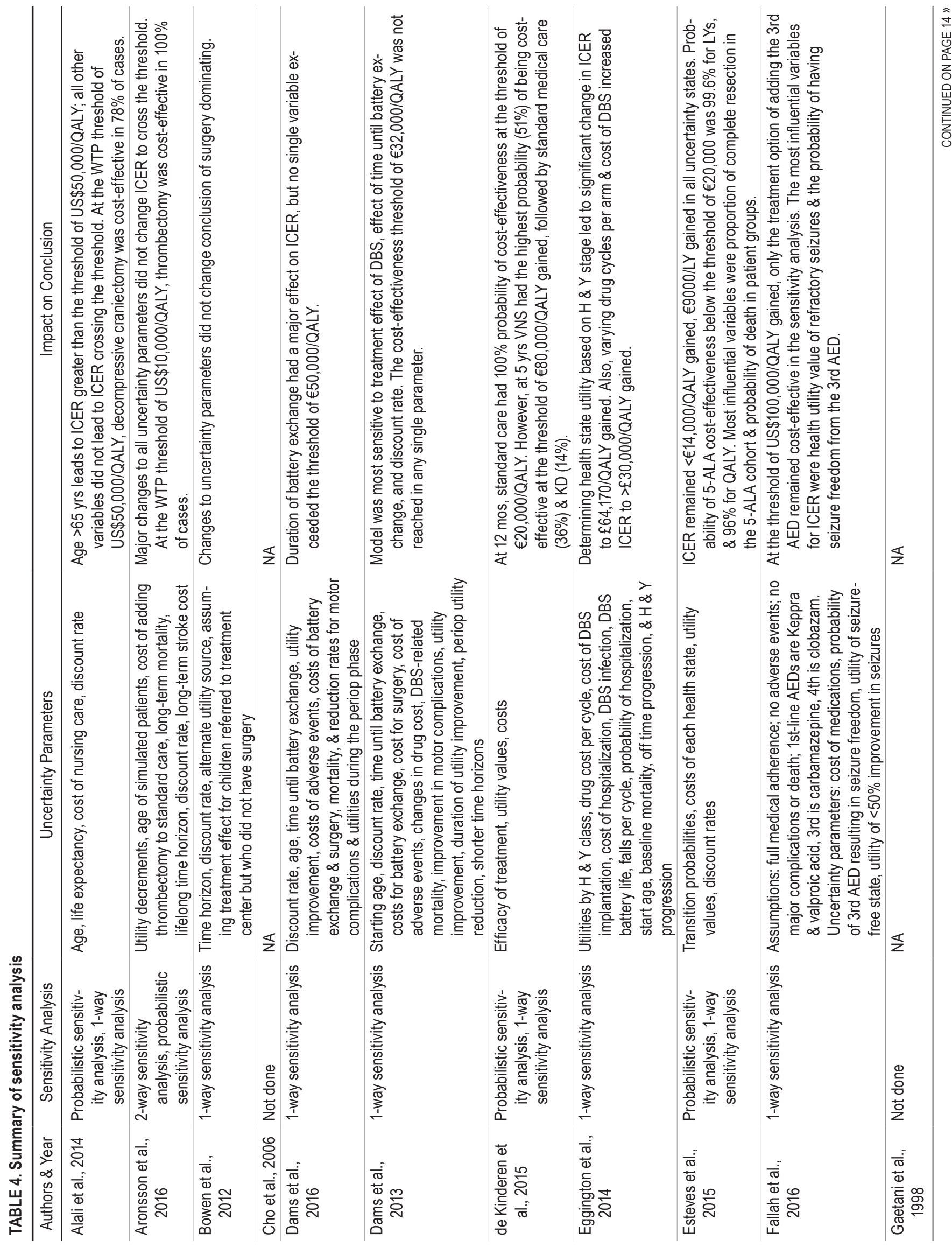




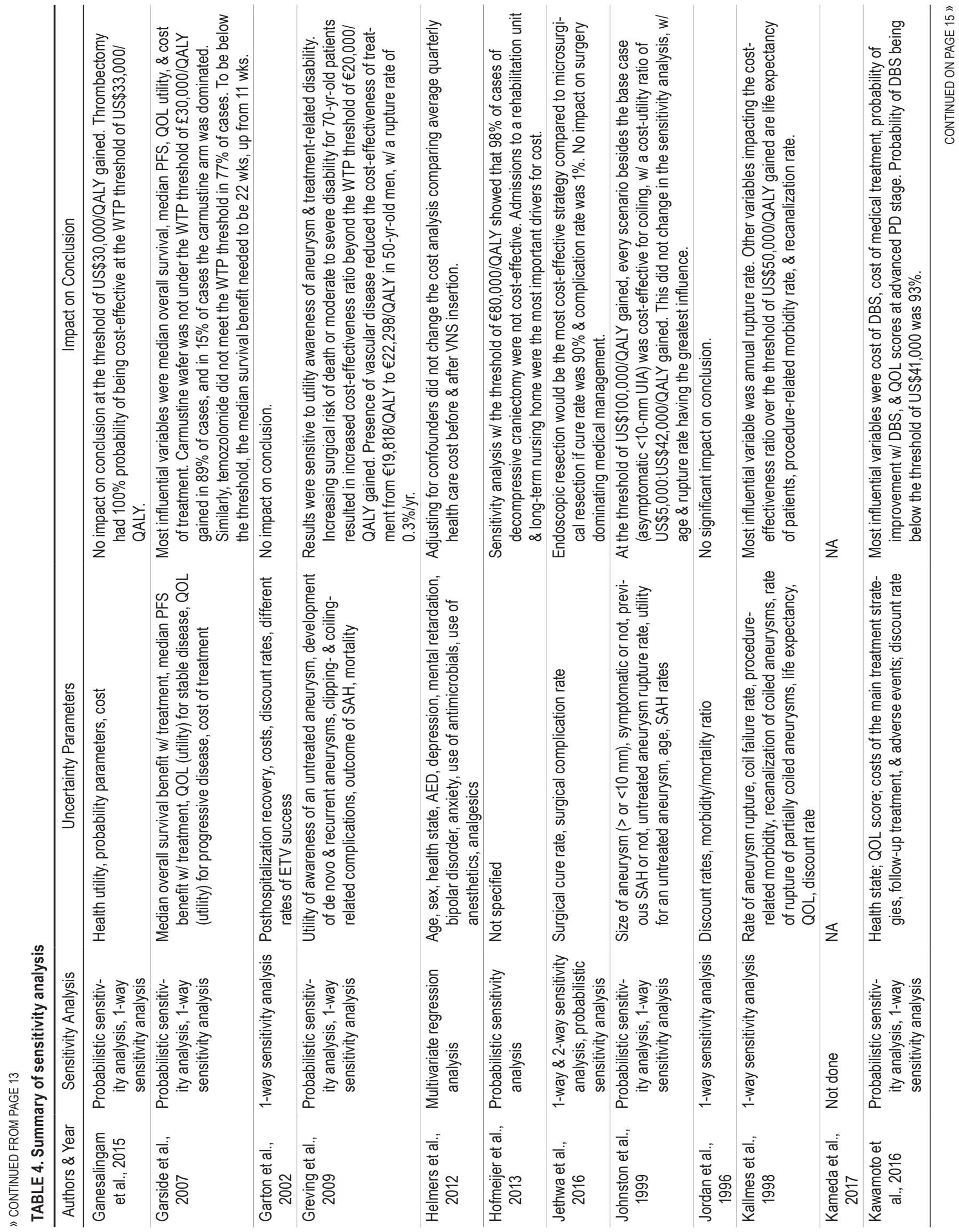




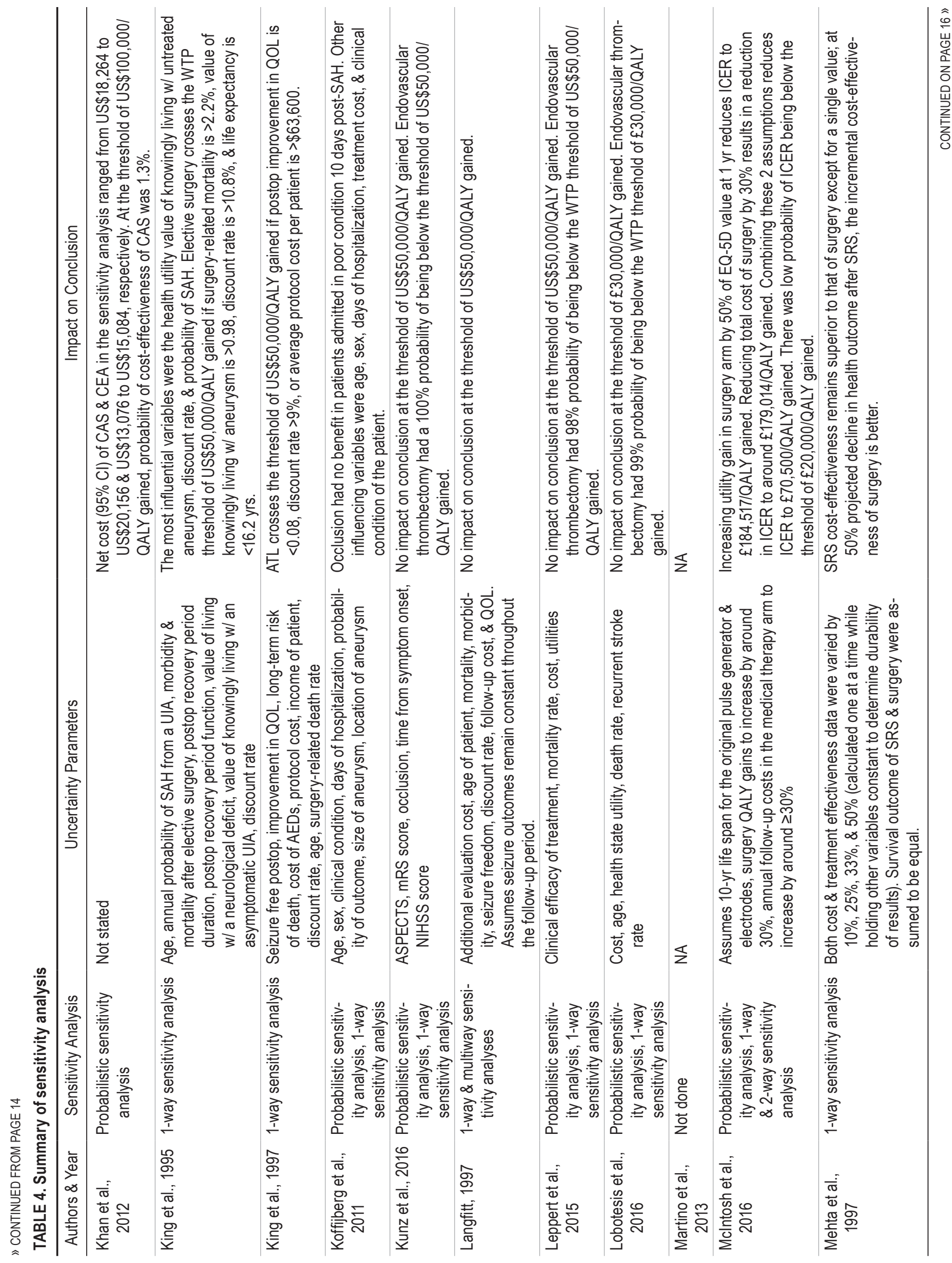




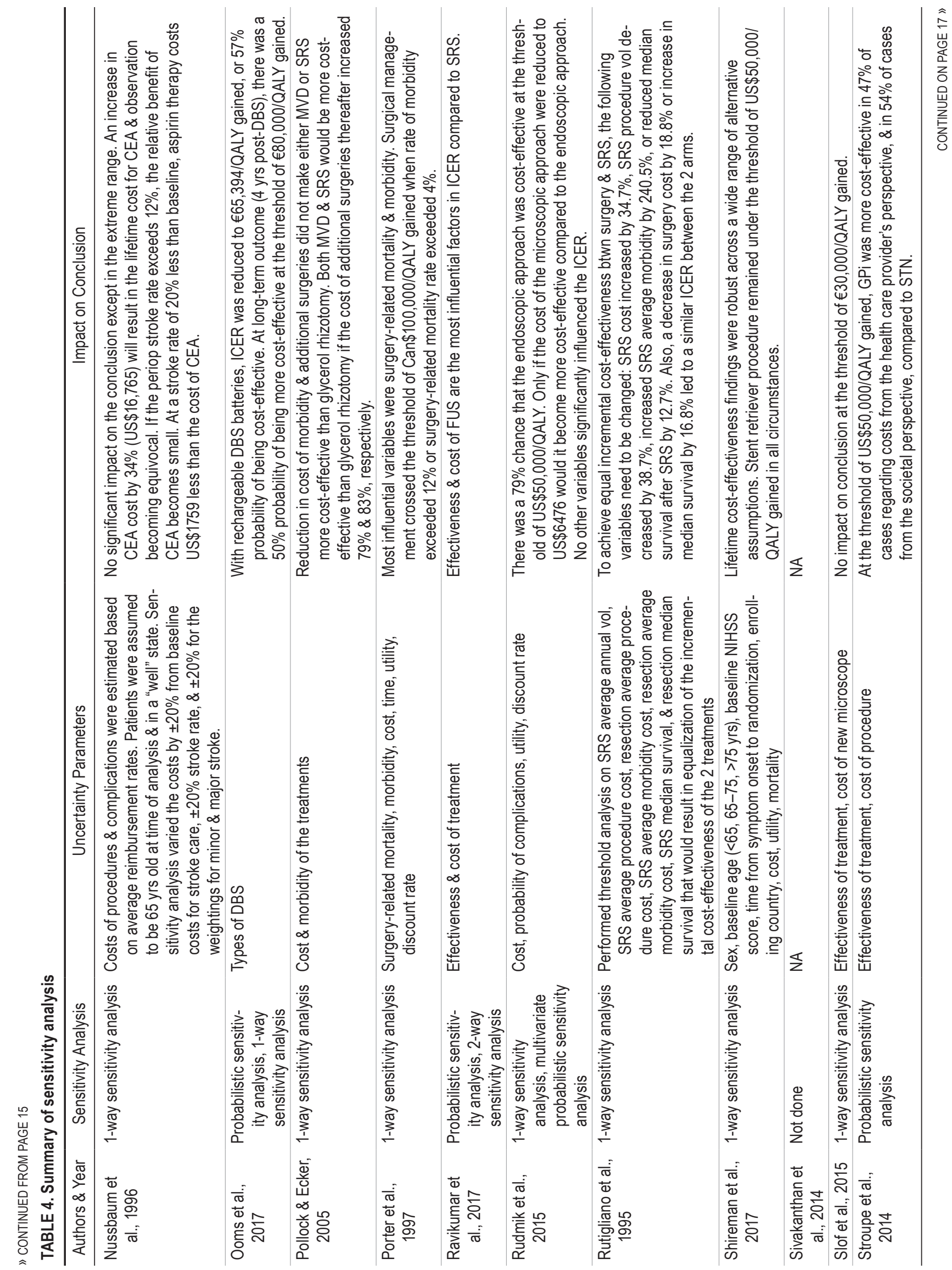


W. H. A. Ryu et al.

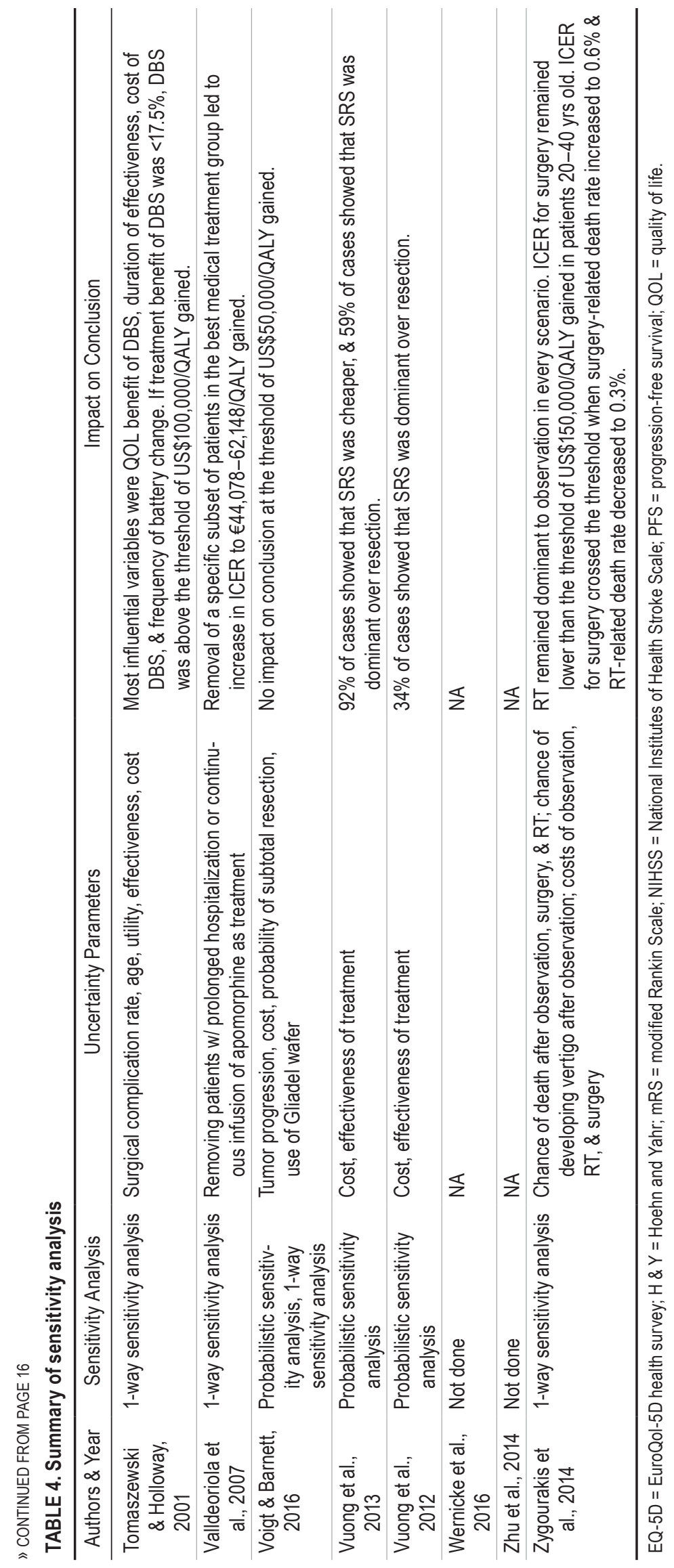


erogeneous for formal meta-analysis methodology. Specifically, the economic modeling, the source of cost and health outcome data, and the sensitivity analysis often differed widely. With the establishment of the Consolidated Health Economic Evaluation Reporting Standards (CHEERS), future methodology should be more standardized. ${ }^{24}$ To address such variability, our review protocol was developed with stringent inclusion criteria that led to the exclusion of many studies that were partial economic evaluations, such as cost comparison studies. In addition, the determination of cost-effectiveness and WTP threshold is influenced by multiple factors and varies by country and health care payer system (i.e., public health care vs private insurance) ${ }^{44}$ The WTP threshold used in this review may not be applicable to all readers, and should be interpreted in the context of their own health care systems. The WTP threshold remains highly variable between studies, with some US-based studies applying the WTP threshold up to US $\$ 150,000 /$ QALY based on the proposal from the WHO of 3 times the gross domestic product per capita. ${ }^{20}$ For this review, the threshold of US\$50,000 per health outcome (QALYs, LYs) was used, given the heterogeneity of the study locations and their associated variability in gross domestic product. Finally, given the high cost of neurosurgical disorders and their treatment options, there may be a potential publication bias, especially for studies supported by industry funding; perhaps studies that show lack of cost-effectiveness may be not submitted for publication.

\section{Conclusions}

There is growing body of cost-effectiveness studies in cranial neurosurgery, especially within the last 5 years. Whereas there are numerous procedures, such as endovascular thrombectomy, that have been conclusively proven to be cost-effective for acute ischemic stroke, there remain promising interventions in our current practice that have yet to meet cost-effectiveness thresholds. This systematic review hopefully highlights the importance of high-quality cost-effectiveness research in neurosurgery, and would urge future clinical trials to incorporate cost-effectiveness into their study design as well as the usual establishment of clinical efficacy.

\section{References}

1. Alali AS, Naimark DM, Wilson JR, Fowler RA, Scales DC, Golan E, et al: Economic evaluation of decompressive craniectomy versus barbiturate coma for refractory intracranial hypertension following traumatic brain injury. Crit Care Med 42:2235-2243, 2014

2. Aronsson M, Persson J, Blomstrand C, Wester P, Levin LA: Cost-effectiveness of endovascular thrombectomy in patients with acute ischemic stroke. Neurology 86:1053-1059, 2016

3. Bowen JM, Snead OC, Chandra K, Blackhouse G, Goeree R: Epilepsy care in Ontario: an economic analysis of increasing access to epilepsy surgery. Ont Health Technol Assess Ser 12:1-41, 2012

4. Brook RH: The role of physicians in controlling medical care costs and reducing waste. JAMA 306:650-651, 2011

5. Cho DY, Tsao M, Lee WY, Chang CS: Socioeconomic costs of open surgery and gamma knife radiosurgery for benign cranial base tumors. Neurosurgery 58:866-873, 2006

6. Dams J, Balzer-Geldsetzer M, Siebert U, Deuschl G, Schuep- bach WM, Krack P, et al: Cost-effectiveness of neurostimulation in Parkinson's disease with early motor complications. Mov Disord 31:1183-1191, 2016

7. Dams J, Siebert U, Bornschein B, Volkmann J, Deuschl G, Oertel WH, et al: Cost-effectiveness of deep brain stimulation in patients with Parkinson's disease. Mov Disord 28:763-771, 2013

8. de Kinderen RJ, Postulart D, Aldenkamp AP, Evers SM, Lambrechts DA, Louw AJ, et al: Cost-effectiveness of the ketogenic diet and vagus nerve stimulation for the treatment of children with intractable epilepsy. Epilepsy Res 110:119131,2015

9. Drummond MF, Sculpher MJ, Claxton K, Stoddart GL, Torrance GW: Methods for the Economic Evaluation of Health Care Programmes, ed 4. United Kingdom: Oxford University Press, 2015

10. Eggington S, Valldeoriola F, Chaudhuri KR, Ashkan K, Annoni E, Deuschl G: The cost-effectiveness of deep brain stimulation in combination with best medical therapy, versus best medical therapy alone, in advanced Parkinson's disease. J Neurol 261:106-116, 2014

11. Esteves S, Alves M, Castel-Branco M, Stummer W: A pilot cost-effectiveness analysis of treatments in newly diagnosed high-grade gliomas: the example of 5-aminolevulinic acid compared with white-light surgery. Neurosurgery 76:552562,2015

12. Fallah A, Weil AG, Wang S, Lewis E, Baca CB, Mathern GW: Cost-utility analysis of competing treatment strategies for drug-resistant epilepsy in children with tuberous sclerosis complex. Epilepsy Behav 63:79-88, 2016

13. Gaetani P, Rodriguez y Baena R, Klersy C, Adinolfi D, Infuso L: A cost-effectiveness analysis on different surgical strategies for intracranial aneurysms. J Neurosurg Sci 42:69-78, 1998

14. Ganesalingam J, Pizzo E, Morris S, Sunderland T, Ames D, Lobotesis K: Cost-utility analysis of mechanical thrombectomy using stent retrievers in acute ischemic stroke. Stroke 46:2591-2598, 2015

15. Garside R, Pitt M, Anderson R, Dyer G, Mealing S, Somerville $M$, et al: The effectiveness and cost-effectiveness of carmustine implants and temozolomide for the treatment of newly diagnosed high-grade glioma: a systematic review and economic evaluation. Health Technol Assess 11:iii-iv, ix-221, 2007

16. Garton HJ, Kestle JR, Cochrane DD, Steinbok P: A costeffectiveness analysis of endoscopic third ventriculostomy. Neurosurgery 51:69-78, 2002

17. Glanville J, Kaunelis D, Mensinkai S: How well do search filters perform in identifying economic evaluations in MEDLINE and EMBASE. Int J Technol Assess Health Care 25:522-529, 2009

18. Goyal M, Menon BK, van Zwam WH, Dippel DWJ, Mitchell PJ, Demchuk AM, et al: Endovascular thrombectomy after large-vessel ischaemic stroke: a meta-analysis of individual patient data from five randomised trials. Lancet 387:17231731,2016

19. Greving JP, Rinkel GJ, Buskens E, Algra A: Cost-effectiveness of preventive treatment of intracranial aneurysms: new data and uncertainties. Neurology 73:258-265, 2009

20. Grosse SD: Assessing cost-effectiveness in healthcare: history of the \$50,000 per QALY threshold. Expert Rev Pharmacoecon Outcomes Res 8:165-178, 2008

21. Helmers SL, Duh MS, Guérin A, Sarda SP, Samuelson TM, Bunker MT, et al: Clinical outcomes, quality of life, and costs associated with implantation of vagus nerve stimulation therapy in pediatric patients with drug-resistant epilepsy. Eur J Paediatr Neurol 16:449-458, 2012

22. Hofmeijer J, van der Worp HB, Kappelle LJ, Eshuis S, Algra A, Greving JP: Cost-effectiveness of surgical decompres- 
sion for space-occupying hemispheric infarction. Stroke 44:2923-2925, 2013

23. Holmes MW, Goodacre S, Stevenson MD, Pandor A, Pickering A: The cost-effectiveness of diagnostic management strategies for children with minor head injury. Arch Dis Child 98:939-944, 2013

24. Husereau D, Drummond M, Petrou S, Carswell C, Moher D, Greenberg D: Consolidated Health Economic Evaluation Reporting Standards (CHEERS) - explanation and elaboration: a report of the ISPOR Health Economic Evaluations Publication Guidelines Task Force. Value Health 16:231-250, 2013

25. Jethwa PR, Patel TD, Hajart AF, Eloy JA, Couldwell WT, Liu JK: Cost-effectiveness analysis of microscopic and endoscopic transsphenoidal surgery versus medical therapy in the management of microprolactinoma in the United States. World Neurosurg 87:65-76, 2016

26. Johnston SC, Gress DR, Kahn JG: Which unruptured cerebral aneurysms should be treated? A cost-utility analysis. Neurology 52:1806-1815, 1999

27. Jordan JE, Marks MP, Lane B, Steinberg GK: Cost-effectiveness of endovascular therapy in the surgical management of cerebral arteriovenous malformations. AJNR Am J Neuroradiol 17:247-254, 1996

28. Kallmes DF, Kallmes MH, Cloft HJ, Dion JE: Guglielmi detachable coil embolization for unruptured aneurysms in nonsurgical candidates: a cost-effectiveness exploration. AJNR Am J Neuroradiol 19:167-176, 1998

29. Kameda M, Yamada S, Atsuchi M, Kimura T, Kazui H, Miyajima M, et al: Cost-effectiveness analysis of shunt surgery for idiopathic normal pressure hydrocephalus based on the SINPHONI and SINPHONI-2 trials. Acta Neurochir (Wien) 159:995-1003, 2017

30. Kawamoto Y, Mouri M, Taira T, Iseki H, Masamune K: Cost-effectiveness analysis of deep brain stimulation in patients with Parkinson's disease in Japan. World Neurosurg 89:628-635, 635.e1, 2016

31. Keehan SP, Cuckler GA, Sisko AM, Madison AJ, Smith SD, Stone DA, et al: National health expenditure projections, 2014-24: spending growth faster than recent trends. Health Aff (Millwood) 34:1407-1417, 2015

32. Kepler CK, Wilkinson SM, Radcliff KE, Vaccaro AR, Anderson DG, Hilibrand AS, et al: Cost-utility analysis in spine care: a systematic review. Spine J 12:676-690, 2012

33. Khan AA, Chaudhry SA, Sivagnanam K, Hassan AE, Suri MF, Qureshi AI: Cost-effectiveness of carotid artery stent placement versus endarterectomy in patients with carotid artery stenosis. J Neurosurg 117:89-93, 2012

34. King JT Jr, Glick HA, Mason TJ, Flamm ES: Elective surgery for asymptomatic, unruptured, intracranial aneurysms: a cost-effectiveness analysis. J Neurosurg 83:403-412, 1995

35. King JT Jr, Sperling MR, Justice AC, O'Connor MJ: A costeffectiveness analysis of anterior temporal lobectomy for intractable temporal lobe epilepsy. J Neurosurg 87:20-28, 1997

36. Koffijberg H, Buskens E, Rinkel GJ: Aneurysm occlusion in elderly patients with aneurysmal subarachnoid haemorrhage: a cost-utility analysis. J Neurol Neurosurg Psychiatry 82:718-727, 2011

37. Kunz WG, Hunink MG, Sommer WH, Beyer SE, Meinel FG, Dorn F, et al: Cost-effectiveness of endovascular stroke therapy: a patient subgroup analysis from a US healthcare perspective. Stroke 47:2797-2804, 2016

38. Langfitt JT: Cost-effectiveness of anterotemporal lobectomy in medically intractable complex partial epilepsy. Epilepsia 38:154-163, 1997

39. Leppert MH, Campbell JD, Simpson JR, Burke JF: Costeffectiveness of intra-arterial treatment as an adjunct to intravenous tissue-type plasminogen activator for acute ischemic stroke. Stroke 46:1870-1876, 2015
40. Lobotesis K, Veltkamp R, Carpenter IH, Claxton LM, Saver JL, Hodgson R: Cost-effectiveness of stent-retriever thrombectomy in combination with IV t-PA compared with IV $\mathrm{t}$-PA alone for acute ischemic stroke in the UK. J Med Econ 19:785-794, 2016

41. Martino J, Gomez E, Bilbao JL, Dueñas JC, Vázquez-Barquero A: Cost-utility of maximal safe resection of WHO grade II gliomas within eloquent areas. Acta Neurochir (Wien) 155:41-50, 2013

42. McIntosh E, Gray A, Daniels J, Gill S, Ives N, Jenkinson C, et al: Cost-utility analysis of deep brain stimulation surgery plus best medical therapy versus best medical therapy in patients with Parkinson's: Economic evaluation alongside the PD SURG trial. Mov Disord 31:1173-1182, 2016

43. Mehta M, Noyes W, Craig B, Lamond J, Auchter R, French $\mathrm{M}$, et al: A cost-effectiveness and cost-utility analysis of radiosurgery vs. resection for single-brain metastases. Int J Radiat Oncol Biol Phys 39:445-454, 1997

44. Nimdet K, Chaiyakunapruk N, Vichansavakul K, Ngorsuraches S: A systematic review of studies eliciting willingnessto-pay per quality-adjusted life year: does it justify $\mathrm{CE}$ threshold? PLoS One 10:e0122760, 2015

45. Nussbaum ES, Heros RC, Erickson DL: Cost-effectiveness of carotid endarterectomy. Neurosurgery 38:237-244, 1996

46. Nwachukwu BU, Schairer WW, Shifflett GD, Kellner DB, Sama AA: Cost-utility analyses in spine care: a qualitative and systematic review. Spine (Phila Pa 1976) 40:31-40, 2015

47. Ooms P, Blankers M, Figee M, Bergfeld IO, van den Munckhof P, Schuurman PR, et al: Cost-effectiveness of deep brain stimulation versus treatment as usual for obsessive-compulsive disorder. Brain Stimul 10:836-842, 2017

48. Panic N, Leoncini E, de Belvis G, Ricciardi W, Boccia S: Evaluation of the endorsement of the preferred reporting items for systematic reviews and meta-analysis (PRISMA) statement on the quality of published systematic review and meta-analyses. PLoS One 8:e83138, 2013

49. Pollock BE, Ecker RD: A prospective cost-effectiveness study of trigeminal neuralgia surgery. Clin J Pain 21:317322, 2005

50. Porter PJ, Shin AY, Detsky AS, Lefaive L, Wallace MC: Surgery versus stereotactic radiosurgery for small, operable cerebral arteriovenous malformations: a clinical and cost comparison. Neurosurgery 41:757-766, 1997

51. Ravikumar VK, Parker JJ, Hornbeck TS, Santini VE, Pauly $\mathrm{KB}$, Wintermark M, et al: Cost-effectiveness of focused ultrasound, radiosurgery, and DBS for essential tremor. Mov Disord 32:1165-1173, 2017

52. Resnick AS, Corrigan D, Mullen JL, Kaiser LR: Surgeon contribution to hospital bottom line: not all are created equal. Ann Surg 242:530-539, 2005

53. Rudmik L, Starreveld YP, Vandergrift WA, Banglawala SM, Soler ZM: Cost-effectiveness of the endoscopic versus microscopic approach for pituitary adenoma resection. Laryngoscope 125:16-24, 2015

54. Rutigliano MJ, Lunsford LD, Kondziolka D, Strauss MJ, Khanna V, Green M: The cost effectiveness of stereotactic radiosurgery versus surgical resection in the treatment of solitary metastatic brain tumors. Neurosurgery 37:445-455, 1995

55. Shemilt I, Thomas J, Morciano M: A web-based tool for adjusting costs to a specific target currency and price year. Evid Policy 6:51-59, 2010

56. Shireman TI, Wang K, Saver JL, Goyal M, Bonafé A, Diener HC, et al: Cost-effectiveness of Solitaire stent retriever thrombectomy for acute ischemic stroke: results from the SWIFT-PRIME Trial (Solitaire With the Intention for Thrombectomy as Primary Endovascular Treatment for Acute Ischemic Stroke). Stroke 48:379-387, 2017 
57. Sivakanthan S, Van Gompel JJ, Alikhani P, van Loveren H, Chen R, Agazzi S: Surgical management of trigeminal neuralgia: use and cost-effectiveness from an analysis of the Medicare Claims Database. Neurosurgery 75:220-226, 2014

58. Slof J, Díez Valle R, Galván J: Cost-effectiveness of 5-aminolevulinic acid-induced fluorescence in malignant glioma surgery. Neurologia 30:163-168, 2015

59. Stroupe KT, Weaver FM, Cao L, Ippolito D, Barton BR, Burnett-Zeigler IE, et al: Cost of deep brain stimulation for the treatment of Parkinson's disease by surgical stimulation sites. Mov Disord 29:1666-1674, 2014

60. Tomaszewski KJ, Holloway RG: Deep brain stimulation in the treatment of Parkinson's disease: a cost-effectiveness analysis. Neurology 57:663-671, 2001

61. Valldeoriola F, Morsi O, Tolosa E, Rumià J, Martí MJ, Martínez-Martín P: Prospective comparative study on costeffectiveness of subthalamic stimulation and best medical treatment in advanced Parkinson's disease. Mov Disord 22:2183-2191, 2007

62. Voigt JD, Barnett G: The value of using a brain laser interstitial thermal therapy (LITT) system in patients presenting with high grade gliomas where maximal safe resection may not be feasible. Cost Eff Resour Alloc 14:6, 2016

63. Vuong DA, Rades D, Le AN, Busse R: The cost-effectiveness of stereotactic radiosurgery versus surgical resection in the treatment of brain metastasis in Vietnam from the perspective of patients and families. World Neurosurg 77:321-328, 2012

64. Vuong DA, Rades D, van Eck AT, Horstmann GA, Busse R: Comparing the cost-effectiveness of two brain metastasis treatment modalities from a payer's perspective: stereotactic radiosurgery versus surgical resection. Clin Neurol Neurosurg 115:276-284, 2013

65. Wernicke AG, Yondorf MZ, Parashar B, Nori D, Clifford
Chao KS, Boockvar JA, et al: The cost-effectiveness of surgical resection and cesium-131 intraoperative brachytherapy versus surgical resection and stereotactic radiosurgery in the treatment of metastatic brain tumors. J Neurooncol 127:145153,2016

66. Zhu XL, Chan DT, Lau CK, Poon WS, Mok VC, Chan AY, et al: Cost-effectiveness of subthalmic nucleus deep brain stimulation for the treatment of advanced Parkinson disease in Hong Kong: a prospective study. World Neurosurg 82:987-993, 2014

67. Zygourakis CC, Kahn JG: Cost-effectiveness research in neurosurgery. Neurosurg Clin N Am 26:189-196, viii, 2015

68. Zygourakis CC, Oh T, Sun MZ, Barani I, Kahn JG, Parsa AT: Surgery is cost-effective treatment for young patients with vestibular schwannomas: decision tree modeling of surgery, radiation, and observation. Neurosurg Focus 37(5):E8, 2014

\section{Disclosures}

Dr. Jacobs is a consultant with Stryker.

\section{Author Contributions}

Conception and design: all authors. Acquisition of data: Ryu, Yang, Muram. Analysis and interpretation of data: all authors. Drafting the article: Ryu. Critically revising the article: all authors. Reviewed submitted version of manuscript: all authors. Approved the final version of the manuscript on behalf of all authors: Ryu. Administrative/technical/material support: Ryu. Study supervision: Ryu, Riva-Cambrin.

\section{Correspondence}

Won Hyung A. Ryu: University of Calgary, AB, Canada. wonhyung.ryu@gmail.com. 